\title{
Human Resource Practices as Antecedents of Employee Performance in the Hotel Industry of Pakistan
}

\author{
Aamir Hayat, Muhammad Azeem, Raheel Nawaz, Muhammad Asif Hasan, Rabia Abdul Rehman \\ MS Student, Department of Management Sciences, COMSATS University Islamabad, Vehari Campus, Pakistan \\ Correspondence Author: Aamir Hayat, MS Student, Department of Management Sciences, COMSATS University Islamabad, Vehari Campus, Pakistan
}

Received date: 18February 2019, Accepted date: 5 April 2019, Online date: 26 April 2019

Copyright: (C) 2019 Aamir Hayat et al., This is an open-access article distributed under the terms of the Creative Commons Attribution License, which permits unrestricted use, distribution, and reproduction in any medium, provided the original author and source are credited.

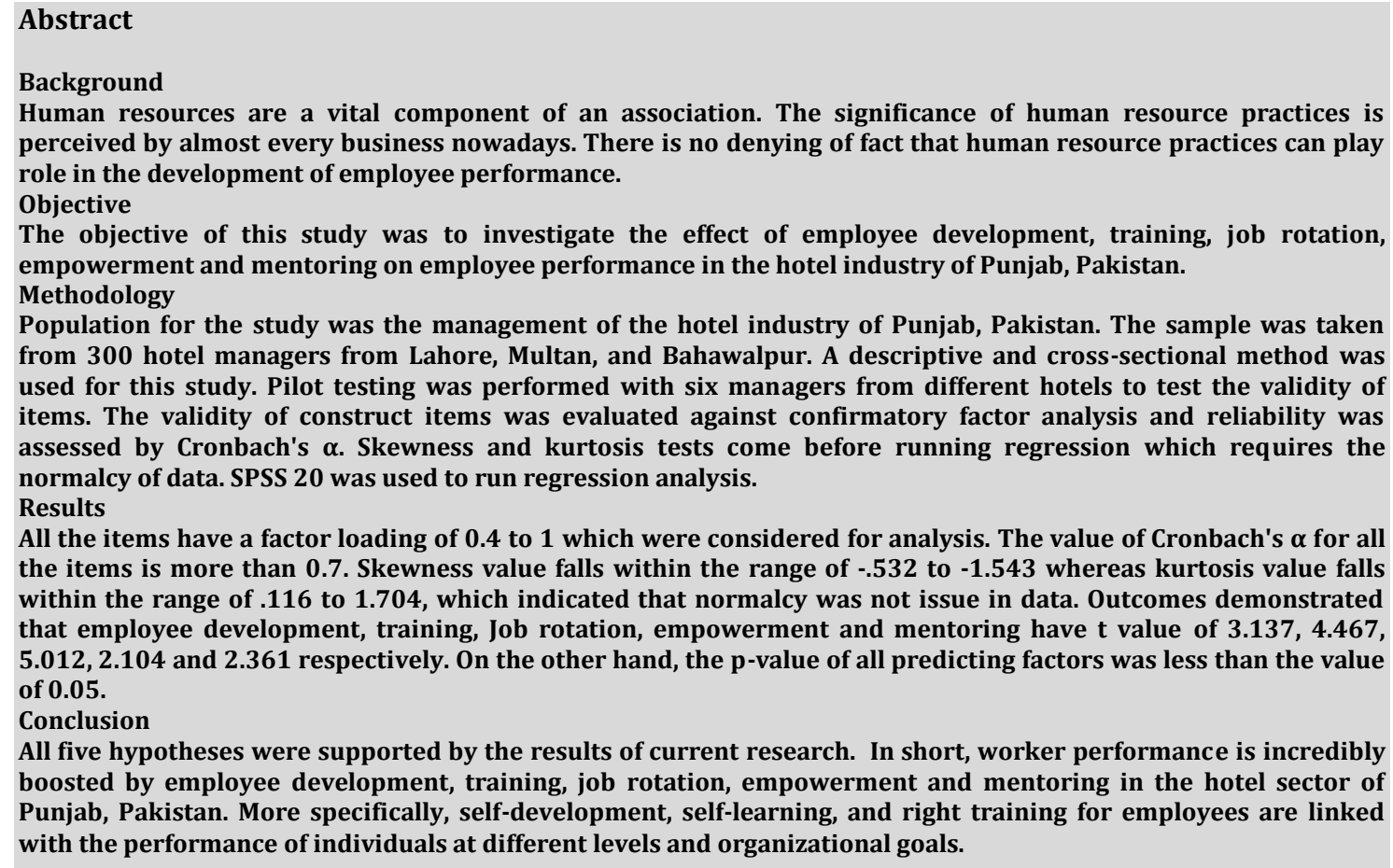

Keywords: Employee Development, Training, Job Rotation, Empowerment, Mentoring and Employee Performance.

\section{INTRODUCTION}

Workers are significant resources of an association. Every worker has distinctive aptitudes, learning, recognition, and experience from different representatives. Performance of staff can be expanded through training, job rotation, mentoring, empowerment and staff development. Overseas firms give incredible significance to worker performance and spend a great deal on previously mentioned factors. Employee training denotes courses that afford personnel with knowledge, fresh expertise, or specialized growth prospects (Amir and Imran, 2013). Without training, workers are not able to perform their duties excellently training results in employee development which adds value to the human capital of a business. High-ranking personnel offer mentoring to junior staff, and it is a one-on-one collaboration (Dessler and Varkkey, 2010). Job rotation means worker perform duties in different departments of an organization at arranged interim to expand their comprehension of all pieces of the business and to assess their capacities (Hakenes and Katolnik, 2017). Empowerment is worker cooperation in the association problems and all the more essential in the necessary leadership process. Empowerment is to enable the labourers to take activities for imaginative practices without anyone else (Zemke and Schaff, 1989). 
Citation: Aamir Hayat, et al., Human Resource Practices as Antecedents of Employee Performance in the Hotel Industry of Pakistan.Australian Journal of Basic and Applied Sciences, 13(4): 11-17.DOI: 10.22587/ajbas.2019.13.4.3

\subsection{Statement of the problem}

There exists a definite link concerning worker development and staff performance. Developed staff is gratified and devoted to employment which results in high work performance (Champathes, 2006). Likewise, human resources performance is equally accelerated by mentoring and feedback. Working on different assignments is prerequisite of human resources development which gives birth to staff performance. Staff performance leads to greater business performance.

\subsection{Research Question}

Is there any influence of work revolution, coaching, training, staff development and empowerment on the performance of human resources?

\subsection{Significance of the study}

This research will empirically contribute to the existing literature by investigating the influence of multiple human resource practices on worker performance.

\subsection{Objective}

The reason for this exploration is to examine diverse factors that impact worker performance. We need to attempt and discover what factor directly or indirectly influence the staff performance. The predictors that impact worker performance are empowerment, training, job rotation, mentoring and employee development. The objective of this study is to understand how training, mentoring, worker development, job rotation and empowerment contribute to worker performance.

\section{Employee Development}

\section{REVIEW OF LITERATURE}

Employee performance is greatly influenced by employee development, job rotation, empowerment, training and mentoring. The common business objective is to earn profit which can be achieved with the help of employee performance. Improvement inabilities of the employee are known as employee development. When the abilities of employee increase, his performance will ultimately be increased, this leads to the organization's effectiveness (Elena and Antonacopoulou, 2000). An organization should find out which employees are willing to learn, and which are not only those employees should be provided mentoring and training who are willing to learn. Skill advancement deeds are significant for the personnel. They indicate that organizations want their development in employee performance (Elena and Antonacopoulou, 2000). Several organizations invest on in their employees for this purpose. It is said that worker growth places great weight on self-development and self-directed education. Workers willingness to learn new things and apply them at work will result in staff improvement which enhances workers performance as well. The following hypothesis is put forth:

H1: Worker development has a positive association with performance of the employee.

\section{Training}

Training simply means incessant variation in demeanor. An arranged and precise exertion to change or create information/ability/demeanor through learning background, to accomplish viable execution in action or scope of exercises, (Roger and Capley, 2009, 2009).An enormous volume of capital is being disbursed on training by corporations to educate its personnel for employment linked responsibilities (Noe et al., 2006). To develop skills to enhance employee performance is known as training (Swanson, 1999). Sattar, T., Ahmad, K., and Hassan, S. M. (2015) in their study indicated that training accelerates worker performance. Training enhances employee performance by improving employee's skills, attitude and understanding to perform work efficiently and effectively which directly enhance organizational performance. Training may be either on the job or off the job. Employees are trained for the following three purposes, namely (Belcourt et al., 2000) to enhance employee's performance, to attain organizational goals, to succeed and compete in the business world. Goals of training for an employee is to excel in his field and for business are to gain competitive advantage. Training bestows information to the representatives concerning various subjects in the association and the correct implementation of these projects leads to more advantages, like, improvement of gainful, versatile just as a proficient association and profitable and mollified workers (Kulkarni and Pallavi, 2013). In short, training enhances employee performance which in turn increases organizational productivity. It is hypothesized as:

H2: Training positively influences worker performance.

\section{Job rotation}

It means placing an employee from one job to another at planned intervals. It is referred to as

"systematic shifting of workers from one assignment to another at planned intervals" (Dessler and Varkkey, 2009; Malinski, 2002). Job rotation implies and incorporates irregular shifting of workers starting with one task then onto the next (Beatty et al., 1987). At the point when the representative performs duty on numerous projects, they adapt fresh aptitudes and increase innovative expertise which makes the activity more intriguing than chipping away at the same occupation (Zeira, 1974). Rotating assignment propels representative and increments their execution. Rotational assignment helps make the employees multitasking and prepare them for a new and different role to play in their field. Working on new assignments makes the job more exciting for employees. Occupation revolution may be within the same functional department or across a diverse department. Nowadays, nearly all corporations devote large volume of amounts of money yearly on training events for practical, executive or workforces growth (Dolezalek, 2005). The amount spent on training may enhance the performance of businesses (Salas and Cannon-Bowers, 2001; Saks and Belcourt, 2006). The corporate world is changing, and the global competition is intense. The consumers want extra superior amenities, and the firms need to have the workforce with lofty inspiration, devotion, and level of sincerity with the 
job to serve the purpose. (Elbadri, 2001; Jamil and Som, 2007; Neff, 2002; Combs and Bourne, 1995; Renaud et al. 2006).Work revolution is an admirable tool for the corporations to the skill development of their personnel (Beatty et al., 1987). Social scientists claim that job revolution is the necessity to meet the challenges to come in different scenarios (Eitington, 1997; Campion et al., 1994). The proposition of job rotation is as follow:

H3: Performance of worker is positively impacted by work rotation.

\section{Empowerment}

It signifies that lower level staff is also involved in decision making and powers are disseminated from top to bottom which positively influences firm performance. Thomas and Velthouse (1990) referred to empowerment as amplified inherent duty inspiration which comes from four factors that are "meaningfulness, competence, choice, and impact". Duvall describes "success is an achievement, accomplishment, and attainment which is the outcome of empowerment". Empowerment leads to employee performance which leads to organizational effectiveness. Empowerment has a positive relationship with employee performance. Sattar, T., Ahmad, K., and Hassan, S. M. (2015) in their study of banking sector specified that empowerment swells worker performance. Employees like an inspiring job as compared to a traditional job. It can be a good trust building measure which will increase employee commitment towards the job. When employees are committed, they will do their job diligently and which in turn will increase organizational effectiveness. In reality, empowerment philosophy is only lip service by their superiors. But if employees are empowered, they can take the right decision at the right time. Fekade Abebe Getachew (2017) in his study found the effects of employees' capacity development on the organizational success the case of US Embassy Addis Ababa, Ethiopia found that employee development results in lofty job performance.

Furthermore, employee empowerment helps in retaining skilled employees which will help business in achieving competitive advantage. Based on the above discussion employee development is hypothesized as:

H4: There is positive link between empowerment and work performance of staff.

\section{Mentoring}

It implies connecting subordinate representative with high-ranking ones to get turnover by their experience. Mentoring is the procedure whereby directors give casual help and backing to specific juniors on a personal premise, to assist them in their endeavours to be effective inside the business (Burke, 1994). Mentoring helps employees to perform well in ever-changing business environ. Mentoring is targets arranged and helps proficient and singular improvement alongside alternate members; it pulls in, energizes, creates, and keeps valuable ability as developing productivity. Corporations frequently need tutoring programs for the accompanying employment: a personnel vocation improvement, a lofty potential advancement, a multiplicity preparing, a Converse coaching, and a Data swap. Christopher (1997) denoted in his study that mentoring accelerates the job performance of workers. Hence based on the preceding review, mentoring is proposed as follow:

H5: Mentoring influences worker performance in a positive way.

\section{Employee Performance}

Performance means explicit demeanor and a group of deeds that people exhibit on their duty (Hosseinian et al., 2007). Campbell refers to performance as demeanor apposite to the fortitude of association that may be reserved letting to the level of immersion (Suliman, 2001). Employee satisfaction, motivation and efficiency, and effectiveness were used to gauge worker performance. In short preparing, rotational task, strengthening and coaching expands worker improvement and representative advancement increments hierarchical execution.

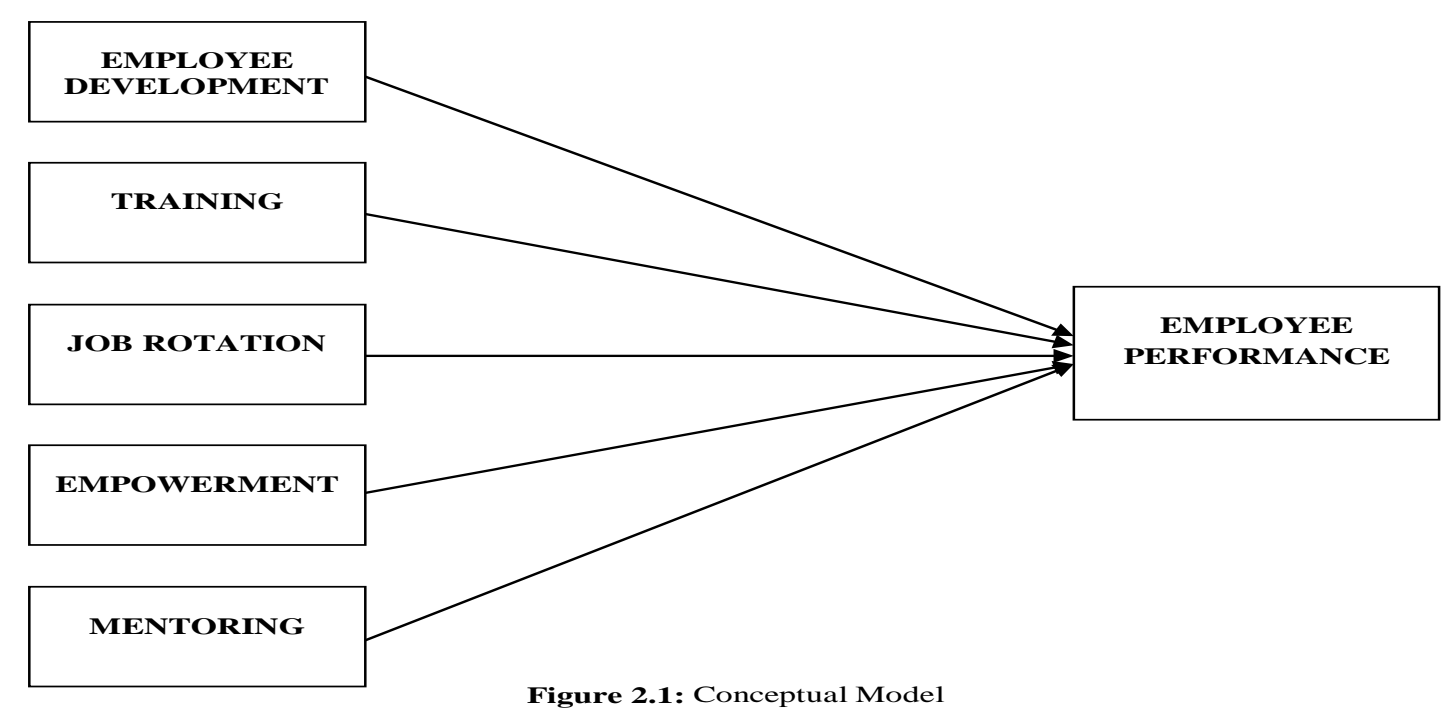


The population of the study is all the management staff of the hotel sector of Punjab, Pakistan. It is hard to gather data from the whole population, so data was collected from a sample of 300 managers of hotel sector from Lahore, Multan, and Bahawalpur. Independent and dependent variables were measured by 28 questions. Training and employee development tool were taken from (yarrow, 2017) which he used in his study. Mentoring and Job rotation tool is the same as was used by (Dansky, 1996; Ho et al., 2009) in his study; Empowerment instrument was adopted from (Zeffane and Zarooni, 2012). Employee performance tool was taken from (Buil et al., 2019). Pilot testing was carried out with six managers from different hotels to test the validity of constructs.

To guarantee the suitability of the factor investigation, Kaiser-Meyer-Olkin (KMO) test for surveying examining sufficiency and Bartlett's trial of sphericity to test for homogeneity of changes were connected for the estimation scales. The consequences of KMO test demonstrated that the insights for every one of the scales were more prominent than 0.50, and Bartlett's test of sphericity uncovered huge measurements for every one of the scales $(\mathrm{p}<0.05)$ inferring that factor examination was fitting. The validity of the research instrument was measured by confirmatory factor analysis whereas the reliability was measured by Cronbach's $\alpha$. Skewness and kurtosis tests come before running regression which requires the normalcy of data. Skewness falls within the range of -.532 to -1.543 whereas kurtosis value falls within the range of .116 to 1.704 which indicated that normalcy was not issued in data. SPSS was used to run a regression to test the hypotheses. Five points Likert scale was used to study responses.

Statistical analysis was performed on SPSS 20.

\section{STATISTICAL ANALYSIS}

Table 1: Reliability Statistics

\begin{tabular}{|c|c|c|}
\hline Variables & Cronbach's $\boldsymbol{\alpha}$ & Items \\
\hline Employee Development & 0.741 & 4 \\
\hline Training & 0.832 & 4 \\
\hline Job Rotation & 0.709 & 3 \\
\hline Empowerment & 0.857 & 5 \\
\hline Mentoring & 0.760 & 6 \\
\hline
\end{tabular}

Table 1 demonstrates the value of Cronbach's $\alpha$ for all the variables which is more than the standard value of 0.7 that confirms the reliability of all the variables. The values of Cronbach's $\alpha$ for employee development, training, job rotation, empowerment, mentoring and employee performance are $0.741,0.832,0.709,0.857,0.760$ and 0.722 respectively. All items are reliable.

Table 2: Factor Analysis

\begin{tabular}{|c|c|c|c|c|c|c|}
\hline Items & Job Rotation & Training & Employee Development & Empowerment & Mentoring & Employee Performance \\
\hline Q \# 1 & 0.571 & 0.627 & 0.488 & 0.531 & 0.784 & 0.654 \\
\hline Q \# 2 & 0.706 & 0.864 & 0.659 & 0.548 & 0.739 & 0.849 \\
\hline Q \# 3 & 0.413 & 0.492 & 0.776 & 0.725 & 0.584 & 0.561 \\
\hline Q \# 4 & & 0.568 & 0.646 & 0.605 & 0.920 & 0.780 \\
\hline Q \# 5 & & & & 0.469 & 0.832 & 0.495 \\
\hline Q \# 6 & & & & 0.683 & 0.583 \\
\hline
\end{tabular}

Table 2 illustrates the factor analysis which is employed to assess the construct validity. Only those items were considered for further evaluation which has factor loading of 0.4 to 1 . Items with a factor loading of < 0.4 were dropped. Outcomes of confirmatory factor analysis (CFA) are $>0.4$ which showed that all items were valid.

Table 3: Correlation Analysis

\begin{tabular}{|c|c|c|c|c|c|c|}
\hline Variables & Employee Development & Training & Job Rotation & Empowerment & Mentoring & Employee Performance \\
\hline $\begin{array}{c}\text { Employee } \\
\text { Development }\end{array}$ & 1 & & & & & \\
\hline Training & $0.603^{* *}$ & 1 & & & & \\
\hline Job Rotation & $0.474^{* *}$ & $0.531^{* *}$ & 1 & & & \\
\hline Empowerment & $0.586^{* *}$ & $0.617^{* *}$ & $0.649^{* *}$ & 1 & & \\
\hline Mentoring & $0.648^{* *}$ & $0.486^{* *}$ & $0.514^{* *}$ & $0.614^{* *}$ & 1 & \\
\hline $\begin{array}{c}\text { Employee } \\
\text { Performance }\end{array}$ & $0.547^{* *}$ & $0.614^{* *}$ & $0.592^{* *}$ & $0.713^{* *}$ & $0.623^{* *}$ & \\
\hline
\end{tabular}

$* * \mathrm{p}=0.01$ (Two-tailed).

Table 3 depicts that all the variables are interrelated with one another positively. Some of them have strong link while most of them are connected moderately. The strongest correlation exists between empowerment and employee performance while the lowest correlation is found between employee development and job rotation. 
Citation: Aamir Hayat, et al., Human Resource Practices as Antecedents of Employee Performance in the Hotel Industry of Pakistan.Australian Journal of Basic and Applied Sciences, 13(4): 11-17.DOI: 10.22587/ajbas.2019.13.4.3

Table 4: Model Summary and Coefficients of Regression Analysis

\begin{tabular}{|c|c|c|c|c|}
\hline \multirow{2}{*}{ Model } & \multicolumn{2}{|c|}{ Unstandardized Coefficients } & \multirow{2}{*}{ T } & \multirow{2}{*}{ Sig. } \\
\cline { 2 - 5 } & B & Std. Error & 4.054 & .000 \\
\hline Constant & .864 & .212 & 3.137 & .001 \\
\hline ED & .261 & .051 & 4.467 & .000 \\
\hline TR & .173 & .034 & 5.012 & .001 \\
\hline JR & .269 & .049 & 2.104 & .000 \\
\hline EM & .131 & .031 & 2.361 & .000 \\
\hline MT & .183 & .037 & & \\
\hline R & $.627^{\text {a }}$ & & & \\
\hline R2 & .483 & & & \\
\hline Adjusted R & .428 & & & .000 \\
\hline Std. Error of Estimate & .345 & & & \\
\hline F & & & & \\
\hline
\end{tabular}

a. Predictors: (Constant), ED, TR, JR, EM, MT

b. Dependent Variable: EP

$*=\mathrm{P}<.05$

The R2 predicts $48.3 \%$ variation in staff performance is owing to employee development, training, job rotation, empowerment and mentoring. $\mathrm{R}$ square clarifies the change amid the dependent variable and independent variable. Additionally, the model is significant as is shown in the table by p-value 0.000 which is less than alpha 0.05 . Employee development has $\beta$ of .261 and $t$ value of 3.137 , and the value of $\mathrm{p}$ is .001 which tells the relationship is statistically significant. $\beta$ of training is .173 with t-value of 4.467 and $p$ less than 0.05 . $\beta$ for job rotation is .269 with $t$-value of 5.012 and $p$-value of .001; employee development has $\beta$ of.131 with t-value of 2.104 and p-value of .000. Last but not the least, $\beta$ for mentoring is .183 with t-value of 2.361 along with a p-value of .000. $\beta$ of all predicting variables is positive, and their t values are higher than benchmark value 1.96 at $95 \%$ confidence level. Moreover, the value of $\mathrm{p}$ for all variables is also statistically significant at such confidence level.

\section{CONCLUSION}

The paper analyzes that worker performance is influenced by worker development, training, job rotation, empowerment, and mentoring. As the results indicate that the leading hypothesis, i.e. human resources development swells performance of people at work, proved to be correct. An employee is the nucleus of the organization. The strength and the development of the corporation are directly reliant on the performance of the employee which is ameliorated by employee development.

The results further endorse that correct training on job enhances the output of the workers. Their efficiency goes higher in the graph through training and skill development. Job rotation is also a helpful tool to boost up the capacity of the employees. They get the experience of different assignments. Previous studies illustrate that work spinning sways employee commitment to onward motivation (Near, 1985). Theoretically, it leads to a greater sense of responsibility among the employees, but the results show that employee empowerment beyond a limit may prove harmful. The outcomes of the current study are in line with (Sattar, T., Ahmad, K., and Hassan, S. M., 2015; Iqbal, Ahmad, and Javaid K, 2013). So, there should be a proper check over the exercise of power after employee empowerment. The last hypothesis also proved to be true. The performance of juniors is immediately dependent on mentoring with the seniors. The spirit of learning by juniors and spirit of cooperation by seniors lead to a productive working environment and provides beneficial results. These factors should be focused aptly for the better performance of the employees.

\section{LIMITATIONS AND RECOMMENDATIONS}

The paper explains the relationship of dependent and independent variables in a well-mannered way, but there is some limitation which restricted the scope of the paper. This study was conducted in a specific industry like hotel sector of Punjab, Pakistan. It is recommended that organizations should adopt the culture of employee development, training, job rotation, empowerment and mentoring for getting better employee performance. This study should be replicated in other sectors to generalize the outcomes of current research. Further studies can add mediating variables like organizational commitment or knowledge management in the existing model. Future research can study the moderating influence of organization culture with the same model.

\section{ACKNOWLEDGEMENT}

I would like to extend my gratitude for Mr. Muhammad Azeem, my best friend who helped me writing and data collection for this article.

\section{REFERENCE}

Amir, E., and A. Imran., 2013.The Effect of Training on Employee Performance European Journal of Business and Management.5(4).

Beatty, R., W., Schneier, C.E., and McEvoy, G.M.1987. Executive development and management succession. Res. Personnel Human Resource Management.5:289-322.

Belcourt, M., Wright, P.and Saks, A. 2000. Performance Management through Training and Development. ITP Nelson, Scarborough. 
Citation: Aamir Hayat, et al., Human Resource Practices as Antecedents of Employee Performance in the Hotel Industry of Pakistan.Australian Journal of Basic and Applied Sciences, 13(4): 11-17.DOI: 10.22587/ajbas.2019.13.4.3

Buil, I., Martínez, E., \&Matute, J. (2019). Transformational leadership and employee performance: The role of identification, engagement and proactive personality. International Journal of Hospitality Management, 77, 64-75.

Burke, R.J., 1984. "Mentors in organizations". Group and Organization Studies, 9(3):353-72.

Casio, W. F., 2000. Costing Human Resources: The Financial Impact of Behavior in Organizations. 4th Ed, Cincinnati, OH: Western.

Champathes, M. R., 2006. Coaching for performance improvement: The coach model. Development and Learning in Organizations.20(2):17-18.

Christopher, O., 1997.The effects of formal mentoring on employee work motivation, organizational commitment and job performance. The Learning Organization. 4(2): 53 - 60

Combs, H.W., and Bourne, S.G., 1995. Quality in business: Preparing retail banking for a competitive environment. Rev. Bus.17(1): 3-6.

Campion, M.A., Cheraskin, L., and Stevens, M.J. 1994. Career-Related Antecedents and outcomes of Job Rotation. Academy Manage. J.37(6): 1518-1542.

Dansky, K. H. (1996). The effect of group mentoring on career outcomes. Group \& Organization Management, $21(1), 5-21$.

Dessler, G., and Varkkey, B., 2010. Human Resource Management, 11th Edition. Delhi: Pearson Prentice Hall.

Dessler, G., and Varkkey, B., 2009. Training and development. Human Resource Management. New Delhi: Dorling Kindersley India Pvt. Ltd, Pp. 304

Dolezalek, H., 2005. 2005 Industry Report. Training. 42(12): 14-28.

Eitington, J.E., 1997. Managing a changing (diverse) workforce. The winning manager: leadership skills for greater innovation, quality and employee commitment. Houston, Taxas: Gulf Publishing Company, p. 239.

Elbadri, A.N.A., 2001. Training practices of polish companies: An Appraisal and Agenda for Improvement. J. Eur. Ind. Train. 25(2): 69-79

Elena, P., and Antonacopoulou. 2000. Employee development through self-development in three retail banks. Journal of Personnel Review. 29 (4): 491-508

Güngör, P., 2011. The relationship between reward management system and employee performance with the mediating role of motivation: A quantitative study on global banks. Procedia-Social and Behavioral Sciences. 24:1510-1520.

Hair, G., Black, B., Babin, B., Anderson, R. and Tatham, R.,2010. Multivariate Data

Ho, W. H., Chang, C. S., Shih, Y. L., \& Liang, R. D. (2009). Effects of job rotation and role stress among nurses on job satisfaction and organizational commitment. BMC health services research, 9(1), 8. 21Analysis. 7th Edition, Pearson, Upper Saddle River, New Jersey.

Iqbal, N., Ahmad, N., and Javaid, K. 2013. Impact of Employee Empowerment on Employee's Performance in the context of Banking Sector of Pakistan. Pinnacle business management.

Jamil, R., and Som, H., 2007. Training Needs Analysis: Practices of Top Companies in Malaysia. Int. Rev. Bus. Res. Pap. 3: 162175.

Kulkarni, and Pallavi, P., 2013. A Literature Review on Training \&Developmentand Quality of Work Life. Journal of Arts, Science and Commerce: University ofPune, India.

Leat, M., 2007. Employee relations and Employment relationships. Exploring employee relations Burlington, MA: Elsevier Ltd, pp. $14-15$

Malinski, R.M., 2002. Job rotation in an academic library: damned if you do and damned if you don't. Lib. Trends. 50(4): 673-80.

Near, J.P., 1985. A discriminant analysis of plateaued versus nonplateaued managers. J. Voc. Beh. $26: 177188$.

Neff, J., 2002. Back to school for P\&G. Advert. Age, 73 (39): 3.

Noe, R. A., Hollenbeck, J. R., Gerhart, B., and Wright, P. M., 2006. Human Resource Management: Gaining a Competitive Advantage. 6th Edt, Boston, MA: McGraw -Hill Irwin.

Ramanan, R. A., Taylor, W. C., Davis, R. B., and Phillips, R. S., 2006. Mentoring matters: mentoring and career preparation in internal medicine residency training. Journal of general internal medicine, 21(4): 340345.

Renaud, S., Morin, L., and Cloutier, J., 2006. Participation in voluntary training activities in the Canadian banking industry. Int. J. Manpower, 27 (7): 666-678.

Robbins, S.P., 1996. Organizational Behavior: Concepts, Controversies, Application. Englewood Cliffs, NJ: Prentice Hall.

Roger, B., and J., capley, 2009.The theory and practice of training.6th edition, London and Philadelphia

Saks, A. M., and Belcourt, M., 2006. An Investigation of Training Activities and Transfer of Training in Organiztions. Human Resource Management, 45 (4): 629-648.

Salas, E., and Cannon-Bowers, J.A., 2001. The science of training: A decade of progress. Ann. Rev. Psychol, 52: $471-499$.

Sattar, T., Ahmad, K., and Hassan, S. M. (2015). Role of human resource practices in employee performance and job satisfaction with mediating effect of employee engagement. Pakistan Economic and Social Review, 53 (1):81-96.

Schein, E.H., 1968. Organizational socialization and the profession of management. Ind. Manage. Rev. 9: 1-15.

Suliman, A. M., 2001. Work performance: is it one thing or many things? The multidimensionality of performance in a Middle Eastern context. International Journal of Human Resource Management, 12(6): 1049-1061.

Swanson, D. L., 1999. Toward an integrative theory of business and society: A research strategy for corporate social performance. Academy of Management Review, 24(3): 506-521.

Thomas, K. W., and B. A. Velthouse., 1990. Cognitive elements of empowerment: An “interpretive" model of intrinsic task motivation. Academy of Management Review 15: 666-681.

Valle, I. D. D., Castillo, M. A. S., and Rodríguez-Duarte, A., 2009.The effects of training on performance in service companies: A data panel study. 
Yarrow, Z. R. (2017). Effect of Training and Development on Employees' Performance: The Case of Equity Bank Kenya(Doctoral dissertation, United States International University-Africa).

Zeffane, R., \& Al Zarooni, H. A. M. (2012). Empowerment, trust and commitment: The moderating role of work-unit centrality. International Journal of Management, 29(1), 332.

Zeira, Y., 1974. Job rotation for management development. Personnel, 51(4): 25-35.

Zemke, R., and Schaff, D., 1989. The service edge: 101 companies that profit from customer care.New York, N.Y. American Library. 